\title{
A Phenomenological Inquiry to Understand Ugandan Farmers' Perceived Barriers to Fertilizer Use
}

\author{
C. Mulvaney ${ }^{1}$, K. D. Kelsey ${ }^{2}$
}

\begin{abstract}
Sub-Saharan African (SSA) countries hold the promise of becoming the second breadbasket of the world if they adopt modern farming practices, including the use of fertilizers and other agricultural inputs. Increasing food production is imminent for all nations, especially in SSA due to the growing global population. Agricultural input adoption, such as fertilizers, leads to an increase in productivity; however, adoption rates among SSA nations remain chronically low. Using a phenomenological lens and qualitative research methods to gather interview data from 30 Ugandan subsistence farmers in situ, we described what and how farmers experienced in regard making decisions to adopt or reject fertilizers. Findings indicated that farmers experienced two poverty traps, resource and cultural beliefs. Recommended interventions include increasing participation in farmer groups and increasing participation in Extension training on the use of agricultural inputs, especially fertilizers.
\end{abstract}

\section{Keywords}

Uganda; fertilizer adoption; qualitative inquiry; poverty trap theory; international development; Extension education.

1. Chandler Mulvaney, Extension Agent I, 4-H Youth Development, UF/IFAS Extension Marion County, University of Florida 2232 NE Jacksonville Rd, Ocala, FL 34470 chandlermulvaney@ufl.edu, https://orcid.org/0000-0002-3030-6604

2. Kathleen D. Kelsey, Professor and Director, Impact Evaluation Unit, University of Georgia 203 Lumpkin House, 145 Cedar St., Athens GA 30602 


\section{Introduction and Problem Statement}

Sub-Saharan African (SSA) countries hold the promise of becoming the second breadbasket of the world if they are able to adopt modern farming practices, including the use of fertilizers and other agricultural inputs (FAO, 2015). Specifically, Uganda is well positioned to advance their agricultural sector with sufficient arable land and labor; however, productivity is hampered by low rates of adoption of modern farming technologies and sufficient application of fertilizers (The World Bank, 2013).

Uganda is a rapidly growing country in SSA with a population primarily comprised of undereducated youth. A third of Uganda's 35 million people are between the ages of 10-24 years and $56 \%$ of the population is under the age of 18 (Uganda Bureau of Statistics, 2010). The majority of Ugandans (72\%) work within the agricultural sector (FAO, 2015); however, farmers lack training in the agricultural sciences, leading to an industry that consistently underperforms given its potential (The World Bank, 2013).

In addition, the majority of farmers suffer from persistent poverty due to poverty traps, defined as living below the nation's poverty line with little opportunity for advancement due to social and economic barriers (Barrett, Garg, \& McBride, 2016). One example of a poverty trap is that farmers infrequently apply agricultural inputs in part because they practice subsistence-farming methods on small plots of land whereby they do not have surplus crops for generating cash to purchase inputs (Banerjee \& Duflo, 2011; Lade et al., 2017). Ugandan farmers reported the lowest rate of fertilizer adoption among SSA countries at 3.2\% (Barrett \& Sheahan, 2017).

The Ugandan government and the Food and Agricultural Organization (FAO, 2015) have emphasized the need to increase production of agricultural commodities to lift farmers and the nation out of poverty; however, attempts to increase agricultural productivity have failed. We sought to describe subsistence farmers' decision-making process for adopting or rejecting fertilizers in the Central Region of Uganda and if poverty traps were a co-variable in making fertilizer adoption decisions.

\section{Theoretical and Conceptual Framework}

A poverty trap is defined as "a situation in which self-reinforcing mechanisms trap people in poverty" (Lade et al., 2017, para 1), whereby "household income or expenditures consistently, or at least on average, fall below the poverty line" (Barrett \& Carter, 2013, para. 4). Poverty traps keep individuals and households in poverty and are caused by structural mechanisms at both macro and micro levels. Macro causes include geography, climate, social networks, social norms, and fixed endowments. Micro causes include mental or physical disability, systemic discrimination, and social exclusion, among other immutable characteristics (Barrett \& Carter, 2013). An example of a poverty trap occurs when declining yields from degraded farms require the poor to farm more intensively on smaller plots, reinforcing the degradation of soils and low agricultural productivity (Enfors, 2013). 
Poverty traps emerge for substance farmers when (a) increases in earnings are scaled below the cost of purchasing inputs, thus minimizing returns on investment such as fertilizers, (b) lower income households have restricted access to financial service, such as credit or insurance, and (c) exclusions occur within social and economic environments such as failure to affiliate with a farmer group or cooperative that would provide access to markets and farming knowledge (Adato, Carter, \& May, 2006; Barrett, Garg, \& McBride, 2016; Chantarat \& Barrett, 2012).

Under these conditions, low-income households face economically stalled situations characterized by low assets and unsuccessful efforts to amass wealth. The poor are often excluded from jobs, social contacts, and access to transportation to pursue income. The initially poor are trapped in persistently low levels of well-being, while initially better-off individuals can parlay wealth into higher levels of well-being (Adato et al., 2006).

Existing poverty traps constrain poor farmers by limiting their access to capital, credit, insurance, and stable markets that are important factors in reducing risk and increasing wealth. In addition, social networks and cultural norms may serve to exclude individuals from growing wealth and assets (Barrett, Garg, \& McBride, 2016). In most cases, the poor will remain so due to social, cultural, and economic environments that disadvantage those already trapped in poverty (Adato et al., 2006; Lade et al., 2017).

Lade et al. (2017) examined the political, social, economic, biophysical and historical settings that limited subsistence farmers from escaping poverty traps. A lack of access to capital and insurance may lead to social exclusion and inequality as farmers were ashamed to appear in public or participate in community activities that would advantage them (Bhalla \& Lapeyre, 2002). Adato et al. (2006) also found that as inequality increased, an individual's social identity became increasingly intertwined with economic status, further trapping them in poverty.

\section{Purpose}

The purpose of the research reported here was to describe subsistence farmers' decisionmaking process for adopting or rejecting fertilizers in the Central Region of Uganda in relationship to the poverty trap conceptual framework (Adato et al., 2006; Lade et al., 2017). Understanding farmers' barriers to fertilizer use and how poverty traps may be a co-variable in nonuse of agricultural inputs is important to assist non-governmental organizations (NGOs) and government Extension agencies in creating approaches to increase fertilizer adoption, thereby reducing poverty in subsistence farming communities in Uganda.

\section{Methods}

The population for the study consisted of 30 subsistence farmers in the Central Region of Uganda. The farmers were criterion selected by in-country staff from the International Fertilizer Development Center (IFDC), an NGO operating globally, and the Ugandan Ministry of 
Agriculture, Animal Industry and Fisheries division. The selection criterion consisted of farmers who belonged to registered farmer groups $(n=22)$ and those who did not $(n=8)$. The researchers used convenience sampling to identify farmers registered in groups, while snowball sampling was employed to generate non-farmer group members to deepen our understanding of emerging social knowledge (Chaim, 2008). Farmer groups in Uganda are formed through the Ministry of Agriculture, Animal Industry and Fisheries Division. Upon the formation of a farmer group, the members are certified in order to lease land, establish access to savings and loan vehicles, and sell harvested crops to reputable buyers.

We invited 30 farmers to participate in the research through key informants in their respective communities. Key informant contacts helped to establish trust and rapport among potential participants (Williamson et al., 2011) and facilitated us in making appointments to visit participants for data collection.

We used phenomenological research design to frame data collection, analysis and reporting (Van Manen, 2014). The central phenomenon addressed was subsistence farmers' decisionmaking process for adopting fertilizers and barriers that limited adoption through the lens of poverty trap theory. The principal researcher acknowledged his bias by searching for a convergence of information among multiple data sources to form themes and draw conclusions (Golafshani, 2003).

The principal researcher traveled to Uganda and conducted interviews with participants in October 2018 on the participants' farms or at the local sub-county building. The interviews were recorded and later transcribed verbatim. An interpreter was present at all 30 interviews. The interpreter assisted with 23 interviews, while seven were conducted in English. The interpreter was Ugandan, spoke seven languages, and held a bachelor's degree from Makerere University in Kampala, Uganda. The interpreter worked as a consultant with the sponsor of the study, International Fertilizer Development Center (IFDC), and external organizations collecting household data with farmers in the region. She was a trusted member of the community. The principal researcher mitigated field issues when using an interpreter by observing responses of both the interpreter and the participant (Williamson et al. 2011), while relaying questions to the interpreter for clarity of perspectives and experiences shared during the interviews. The principal researcher acknowledged that all information disclosed during each of the thirty interviews was interpreted by one party, making precision a limitation of the study.

However, to enhance quality and validity we (a) conducted a literature review to determine the interview protocol, (b) collected data from participants using face-to-face interviews in situ, (c) transcribed the interviews verbatim and sent the transcripts to the interpreter for verification (unfortunately, member checking was not conducted with the participants due to communication barriers), (d) analyzed the transcripts line-by-line to highlight significant statements (open coding) using Atlas.ti software (Saldana, 2015), and (e) clustered the significant statements into themes that enabled us to draw conclusions regarding the phenomena. We added participants' quotations in the findings to establish truth-value. To ensure anonymity, we used pseudonyms (Tracy, 2010; Van Manen, 2014). 


\section{Findings}

Overall, farmers experienced several barriers to adopting agricultural practices that were consistent with the literature on poverty traps (Barrett \& Carter, 2013; Barrett, Garg, \& McBride, 2016; Chantarat \& Barrett, 2012). Farmers were interested in learning about new farming innovations that would facilitate consistent and appropriate use of fertilizers but were constrained by cultural beliefs, social networks, social norms, and economic resource traps.

All of the farmers reported farming out of necessity versus choice, as they had limited options for pursuing economic opportunities outside of working for a farmer or becoming a farmer by acquiring credit or small plots of land or both.

We classified the participants into two groups, those who did not associate with a farmer group $(n=8)$ and those who did $(n=22)$ (see Table 1). Farmers who associated with farmer groups in all cases except one (Sarama), served as the chairperson for the group. Sarama served as the secretary and treasurer for her farmer group (Table 1). Farmer group members were poor but reported reduced levels of poverty stress due to slight increases in household income.

\section{Theme 1: Systemic Poverty Resulted in Reduced Motivation to Use Fertilizers}

Claim: Farmers desired to use fertilizers but could not afford to consistently purchase them due to a lack of income.

Supporting Evidence: All but one (Sadah) farmer used organic or mineral fertilizers or both inconsistently as they were unable to reliably buy fertilizers and hire labor due to a lack of cash or credit. The primary barrier to adoption was an inability to pay for fertilizers after purchasing basic household necessities such as food, water, and school fees for their children's education. Often, even these necessities were forgone due to poverty.

A lack of resources sustained systemic poverty and reduced farmers' motivation to adopt new technologies beyond what they learned from their parents, who were also subsistence farmers. Zaharrah reported she was stuck in "a little hole," unable to move by making changes such as adopting agricultural innovations and inputs due to a lack of cash and credit. She said, We lack [items needed for farming] at times. If we are cultivating tomatoes, you need a system for spraying and watering, watering cans, those tools [needed] for agriculture. We lack all of those things that help in agriculture. So we have to struggle in a small hole. You cannot move anywhere. Yes, if you have such things, you can help your farm, you can grow crops on a large scale because this little hole here will take you nowhere, and you cannot move (371-385).

All of the participants reported feeling uncertain about how to overcome the challenges they faced to escape poverty. Fourteen farmers reported that fertilizer affordability was the main barrier to adoption. 
Table 1

Demographic Profile of Farmers

\begin{tabular}{|c|c|c|c|c|c|}
\hline $\begin{array}{c}\text { Pseudonym and } \\
\text { Gender }\end{array}$ & District & Age & $\begin{array}{c}\text { Educational } \\
\text { Level }^{\mathrm{abc}}\end{array}$ & Dependents $^{d}$ & $\begin{array}{c}\text { Fertilizer } \\
\text { Use }\end{array}$ \\
\hline \multicolumn{6}{|c|}{ Farmers not Associated with a Farmer Group } \\
\hline Caliana, F & Budaka & 49 & S3 & 5 & Organic \\
\hline Dawda, F & Budaka & 64 & S1 & 14 & Both \\
\hline Farya, F & Budaka & 35 & $\mathrm{~S} 2$ & 8 & Organic \\
\hline Kali, F & Budaka & 27 & S4 & 5 & Organic \\
\hline Laila, F & Budaka & 45 & P7 & 12 & Both \\
\hline Mada, F & Budaka & 30 & P7 & 8 & Organic \\
\hline Mae, F & Budaka & 35 & P5 & 7 & Organic \\
\hline Saleem, M & Budaka & 46 & S3 & 10 & Both \\
\hline \multicolumn{6}{|c|}{ Farmers Associated with a Farmer Group } \\
\hline Aaden, M & Mbale & 58 & P6 & 15 & Both \\
\hline Abby, $F$ & Mbale & N/A & S3 & 14 & Both \\
\hline Abdulla, M & Mbale & 34 & $\mathrm{~S} 2$ & 9 & Organic \\
\hline Abraham, M & Butaleja & 35 & P3 & 13 & Organic \\
\hline Ali, F & Tororo & 50 & S4 & 10 & Both \\
\hline Amare, $\mathrm{F}$ & Budaka & 40 & P3 & 5 & Mineral \\
\hline Ami, F & Butaleja & 55 & None & 3 & Organic \\
\hline Asha, F & Tororo & 52 & P7 & 12 & Organic \\
\hline Esther, F & Tororo & 51 & S4 & 10 & Mineral \\
\hline Halah, F & Butaleja & 46 & P3 & 15 & Mineral \\
\hline Kwame, F & Butaleja & 48 & $\mathrm{~S} 2$ & 11 & Both \\
\hline Moses, F & Mbale & 56 & P2 & 8 & Both \\
\hline Noah, M & Tororo & 59 & Bachelor & 2 & Mineral \\
\hline Ode, F & Budaka & 32 & Bachelor & 2 & Both \\
\hline Omari, M & Butaleja & 36 & S4 & 4 & Both \\
\hline Rabea, F & Tororo & 31 & S3 & 6 & Mineral \\
\hline Sabah, F & Butaleja & 30 & P7 & 10 & Both \\
\hline Sadah, F & Mbale & N/A & P5 & 8 & None \\
\hline Sarama, F & Butaleja & 47 & U Bachelor's & 3 & Both \\
\hline Zaharah, F & Tororo & 53 & $\mathrm{~S} 4$ & 7 & Organic \\
\hline Zakai, F & Butaleja & 58 & P7 & 12 & Mineral \\
\hline Zane, F & Budaka & 75 & $\mathrm{~S} 2$ & 20 & Both \\
\hline
\end{tabular}

Note. ${ }^{\mathrm{P}} \mathrm{P}=$ Primary school level achieved. ${ }^{\mathrm{b}} \mathrm{S}=$ Secondary school level achieved. ${ }^{\mathrm{C}} \mathrm{U}=$ University education. ${ }^{d}$ Denotes the number of immediate family members the farmer was responsible for housing and feeding, including adopted children. 'Denotes the type of fertilizers the farmers used. Both denotes the use of mineral and organic fertilizers. None denotes farmers' nonadoption of any fertilizer inputs. 


\section{Theme 2: Fertilizers Equate to Increased Yields}

Claim: Participants believed that fertilizer use increased yields and would use them if they had the resources to purchase them.

Supporting Evidence: Despite the existing poverty that affected all of the participants, farmers valued fertilizer use over all other inputs they had adopted in the past. When asked why they were motivated to use fertilizer, Zaharrah said,

The yield, the yield! Because people who are using fertilizers you find they are getting a bumper harvest. Some good, good harvest. Even the soil remains fertile.

The moment you apply, the soil changes and the fertility is boosted (276-278).

Eleven farmers reported that fertilizers increased their yields when applied to a crop. Ode, a consistent user of both organic and mineral fertilizers, mentioned that when he used fertilizers on his crops, he was "assured of good yields" (193-194).

Nineteen farmers believed that fertilizers were directly associated with increased yields, despite that fact that 17 of the 19 farmers had not received any formal fertilizer training. Despite the lack of formal knowledge and training regarding fertilizer use, farmers were confident in fertilizers' ability to positively affect crop yields and provide an increase in one's profitability.

\section{Theme 3: Farmers Felt Cheated by the Government, Agricultural Buyers and Consumers}

Claim: Farmers reported feeling cheated by the government, agricultural buyers, and consumers resulting in lost income to advance their farming practices and receive fair prices for their crops.

Supporting Evidence: All 30 farmers reported financial stress. Eleven farmers reported feeling cheated by the government, market buyers, and consumers. Noah said,

There was one time a group came and they gave us seed for soybeans and they told us they would get us a market [to sell]. So we planted and then the people disappeared. Then, we got stuck with all of this soybean in our house and had to sell for cheap. People got discouraged to grow soybean. Some people will use tricks to convince farmers to grow something and then cheat us into [poor] prices later (304-308).

Noah spoke about the poverty trap that existed within his household. Farmers attempted to break free from poverty by trusting agricultural buyers. However, after the agricultural buyers abandoned them, farmers feel devalued by the system that was supposed to support them.

Eleven farmers cited access to markets and transportation issues as barriers to wealth. Esther, a farmer who lacked access to transportation from the fields to the market, said, After harvesting, those people [buyers] just disappear and they send people to come and cheat you from your products. Then, you must search for a person to buy. It was promised that the person would buy for a certain price. But when they come back, they do not remember the agreed upon price and try to cheat you (308-310). 
Mada also reported that she was cheated by agricultural buyers. She said, We depend on the buyers. We [farmers] don't have bargaining power because what they [buyers] give you is what you take. At the end of the day, they [buyers] are selling it at a much higher price but we depend on them [buyers] because what they say is what we take. Take it or leave it. We depend on the local methods and buyers for our crops (495-500).

Inconsistent prices and market conditions affected farmers' ability to buy seeds and hire labor. Despite a desire to adopt fertilizers, ten farmers believed that corrupt governmental employees and market buyers abused their power during peak sell-off times by offering below market prices, thus, draining farmers' small savings. Ode said, Some of the challenges are the prices; there are no stable prices. We are seriously engaging in farming but the bias [of the governmental employees and agricultural buyers] always determine the prices. So they are not even considering us (224-226).

With limited transportation availability to markets farmers traded with unscrupulous buyers, receiving marginal prices for their crops, leading to a poverty trap. Farmers' feeling cheated in the existing market system eroded their confidence in buying fertilizers as the investment may not be returned.

\section{Theme 4: No Other Way - We Are Trapped in Farming}

Claim: Farmers were trapped in a subsistence farming lifestyle with no path to additional income or alternative employment.

Supporting Evidence: Twenty-eight farmers said that subsistence farming was their only employment option. When asked why he continued to farm, Omari said, "farming is what you rely on. You get food and in the case of plenty, I sell some to earn a living" (96-97). These farmers were in a subsistence farming trap, with no opportunity to escape based in part on their identity as substance farmers.

For half of the participants, farming was their only option for survival. Sabah said, "there was a moment when poverty was too much and I felt like I could hardly even afford a meal. So I was forced to go and work in the rice fields" (23-25). The participants believed they were trapped in subsistence farming because they possessed limited skills and training for other work. However, all of the participants expressed hope for the future, despite their reported barriers to generating wealth from farming. When asked why he continued to farm, Noah said, "I know farming but the problem is we are just doing it locally because God has given us an ability. So, it is my prayer that God helps us, trains us and gives us new skills" (21-23).

Farmers desired to improve their economic and social status but lacked external macro support structures to do so such as fertilizer application training from government Extension agencies and NGOs, lack of access to credit and cash, and a lack of stable markets. Therefore, they remained in a cultural and resource trap. 


\section{Conclusions, Discussion, and Recommendations}

Our findings uncovered two poverty traps to explain why farmers did not adopt fertilizers, a cultural trap and a resource trap (Barrett \& Carter, 2013; Chantarat \& Barrett, 2012; Lade et al., 2017). Farmers' cultural identity as subsistence farmers prevented them from escaping poverty, leading to "persistent poverty as the natural consequence of the group-defining characteristic, resulting in a single equilibrium poverty trap" (Barrett, Garg, \& McBride, 2016, para 9). The culmination of external factors combined to de-motivate farmers' who understood the value of fertilizers when applied appropriately but lacked the knowledge and capital to access fertilizers. The implications of the two poverty traps identified in this study resulted in farmers' feeling stuck in poverty, with few opportunities to access capital and markets.

In addition, the cultural trap was rooted in farmers' belief that there were no other options for employment. Because all of the participants came from subsistence farming families, their families expected them to continue in that vocation. Economic and social constraints limited their opportunity for professional growth, despite a desire to do so. To further compound the lack of opportunity for social growth, farmers' who participated in the study felt trapped in their current occupation, as described in theme four. The knowledge of alternative lifestyles and new technology was limited, resulting in culturally imposed limitations.

The resource trap included economic vulnerability from unpredictable markets and a lack of access to credit, labor, transportation, agricultural inputs, and Extension training. With a lack of control in the markets, farmers reported feeling devalued and cheated by governmental employees, agricultural buyers, and consumers. The resource trap left farmers with little motivation to adopt new agricultural practices, deepening the cycle of poverty. Not belonging to a farmer group was important for understanding social exclusion and how it reinforced the poverty trap as the chronically poor associated mainly with similar others, who also lacked knowledge and resources (Chantarat \& Barrett, 2012).

Alleviating poverty traps requires a multi-pronged approach and is dependent on national and international policy to support and protect farmers from exploitation. Barrett, Garg, and McBride (2016) recommended initiatives that could move people out of poverty traps, including investments in assets such as farm equipment, adoption of agricultural production technologies and inputs, participation in remunerative markets, credit and insurance programs, safety net programs, education, and entrepreneurial activities. Transfer programs (giving cash directly to the poor) are also an effective policy for addressing poor sociocultural identities in the short term (Barrett \& Carter, 2013).

While these issues are beyond the scope of this study, we recommend that NGOs and government Extension agencies serving farmers in SSA provide educational programs to empower farmers to gain memberships in farmer groups as an important first step (Sigman, Chibwana, \& Matenje, 1994). Farmer groups can serve as collective groups to provide individuals with access to inputs and farm tools through cooperative social structures. Additionally, future research should be conducted on the impact of participation in a farmer 
group and the potential relationship that increased knowledge has on fertilizer adoption or rejection in Uganda.

Farmers would benefit from targeted educational programs focusing on best practices for applying agricultural inputs, including fertilizers (Bunyatta et al., 2005). Such programs could be implemented through existing Extension programs with the Ugandan National Agricultural Advisory Development Services (NAADS) and external NGOs. Educational opportunities serve to integrate new technology into the community, leading to economic growth, and reducing both types of poverty traps identified in this study.

\section{References}

Adato, M., Carter, M. R., \& May, J. (2006). Exploring poverty traps and social exclusion in South Africa using qualitative and quantitative data. The Journal of Development Studies, 42(2), 226-247. https://doi.org/10.1080/00220380500405345

Banerjee, A. V., \& Duflo, E. (2011). Poor economics: A radical rethinking of the way to fight global poverty. New York, NY: Public Affairs.

Barrett, C. B., \& Carter, M. R. (2013). The economics of poverty traps and persistent poverty: Empirical and policy implications. Journal of Development Studies, 49(7), 976-990. https://doi.org/10.1080/00220388.2013.785527

Barrett, C. B., Garg, T., \& McBride, L. (2016). Well-being dynamics and poverty traps. Annual Review of Resource Economics, 8, 303-327. https://doi.org/10.1146/annurev-resource$\underline{100815-095235}$

Barrett, C. B., \& Sheahan, M. (2017). Ten striking facts about agricultural input use in SubSaharan Africa. Food Policy, 67, 12-25. https://doi.org/10.1016/j.foodpol.2016.09.010

Bhalla, A., \& Lapeyre, F. (2002). Social exclusion: Towards an analytical and operational framework. Development and change, 28(3), 413-433. https://doi.org/10.1111/1467$\underline{7660.00049}$

Bunyatta, D. K., Mureithi, J. G., Onyango, C. A., \& Ngesa, F. U. (2005). Farmer field school as an effective methodology for disseminating agricultural technologies: Up-scaling of soil management technologies among small-scale farmers in Trans-Nzoia district, Kenya. Proceedings of the 21st Annual conference of the Association for International Agricultural and Extension Education, San Antonio, TX, 515-525.

Chaim, N. (2008). Sampling knowledge: The hermeneutics of snowball sampling in qualitative research. International Journal of Social Research Methodology, 11(4), 327-344. https://doi.org/10.1080/13645570701401305 
Chantarat, S., \& Barrett C. B. (2012). Social network capital, economic mobility and poverty traps. Journal of Economic Inequality, 10(3), 299-342. https://doi.org/10.1007/s10888$\underline{011-9164-5}$

Enfors, E. (2013). Social-ecological traps and transformations in dryland agro-ecosystems: Using water system innovations to change the trajectory of development. Global Environmental Change 23(1), 51-60. https://doi.org/10.1016/j.gloenvcha.2012.10.007

Food and Agriculture Organization of the United Nations. (2015). Responding to the challenges of poverty, food insecurity and climate change. Country programming framework 20152019. Kampala, Uganda. Retrieved from http://www.fao.org/3/a-bp628e.pdf

Golafshani, N. (2003). Understanding reliability and validity in qualitative research. The Qualitative Report, 8(4), 597-606. http://www.nova.edu/ssss/QR/QR8-4/golafshani.pdf

Lade, S. J., Haider, L. J., Engström, G., \& Schlüter, M. (2017). Resilience offers escape from trapped thinking on poverty alleviation. Science Advances, 3(5), e1603043. https://doi.org/10.1126/sciadv.1603043

Saldaña, J. (2015). The coding manual for qualitative researchers. Thousand Oaks, CA: Sage.

Sigman, V. A., Chibwana, C., \& Matenje, I. (1994). Reaching Malawian smallholder farmers with agricultural extension programs: A case for increased use of women-farmer groups. Journal of International Agricultural and Extension Education, 1(2), 35-41. doi: 10.5191/jiaee.1994.01206

The World Bank. (2013). Remarkable declines in global poverty, but major challenges remain. Retrieved from http://www.worldbank.org/en/news/pressrelease/2013/04/17/remarkable-declines-in-global-poverty-but-major-challengesremain

Tracy, S. J. (2010). Qualitative quality: Eight "Big-Tent" criteria for excellent qualitative research. Qualitative Inquiry, 16(10), 837-851. https://doi.org/10.1177/1077800410383121

Uganda Bureau of Statistics. (2010). Summary Report on Uganda Census of Agriculture 2008/2009. Volume 1. Kampala, Uganda. Retrieved from https://www.ubos.org/wpcontent/uploads/publications/03 2018UCASummary.pdf

Van Manen, M. (2014). Phenomenology of practice: Meaning-giving methods in phenomenological research and writing. Walnut Creek, CA: Left Coast Press. 
Williamson, D. L., Choi, J., Charchuk, M., Rempel, G. R., Pitre, N., Breitkreuz, R., \& Kushner, K. E. (2011). Interpreter-facilitated cross-language interviews: A research note. Qualitative research, 11(4), 381-394. https://doi.org/10.1177/1468794111404319

(C) 2020 by authors. This article is an open access article distributed under the terms and conditions of the Creative Commons Attribution license (http://creativecommons.org/licenses/by/4.0/). 